\title{
SERVIÇOS INOVADORES EM BIBLIOTECA UNIVERSITÁRIA
}

\section{INNOVATIVE SERVICES IN UNIVERSITY LIBRARY}

\author{
Tatiana Rossia \\ Ana Clara Cândidob \\ Ana Verónica Pazminoc \\ William Barbosa Viannad
}

\begin{abstract}
RESUMO
Introdução: As bibliotecas universitárias prestam serviços de informação que necessitam estarem adequados as necessidades do corpo docente, discente e administrativo. Para isso continuamente os serviços sofrem remodelações. Verificar o que está sendo publicado sobre serviços inovadores e tendências ou o que tem sido ofertado em outras bibliotecas é uma vertente a ser seguida. Objetivo: Identificar os serviços inovadores que estão sendo publicados e prestados nas bibliotecas universitárias brasileiras. Metodologia: Foi empregada a pesquisa bibliográfica nas bases nacionais BRAPCI e SciELO e a pesquisa documental nos sites das bibliotecas das dez melhores universidades brasileiras e dez mais inovadoras. Resultados: Observou-se que a maior parte dos estudos na área de Ciência da Informação recuperados não aborda puramente a inovação e que poucos serviços podem ser apontados como inovadores nas bibliotecas brasileiras pesquisadas. Conclusões: Verificou-se que as bibliotecas universitárias estão promovendo inovação em seus serviços informacionais sendo que isso é possível por meio de parcerias, novas ideias, treinamento e colaboração da equipe, desenvolvimento e/ou aquisição de ferramentas e equipamentos.
\end{abstract}

Descritores: Serviços de informação. Serviços de biblioteca. Inovação de serviços. Bibliotecas universitárias.

a Doutoranda em Ciência da Informação pelo Programa de Pós-Graduação em Ciência da Informação da Universidade Federal de Santa Catarina (PGCin-UFSC). Bibliotecária na Biblioteca na Universidade Federal de Santa Catarina (UFSC). E-mail: tat.caua@gmail.com.

b Doutora em Avaliação de Tecnologia pela Universidade Nova de Lisboa (FCT-UNL) Portugal. Professora do Departamento de Ciência da Informação e do Programa de PósGraduação em Ciência da Informação da Universidade Federal de Santa Catarina (PGCinUFSC. E-mail: ana.candido@ufsc.br.

c Doutora em Design pela Pontifícia Universidade Católica do Rio de Janeiro (PUC-RJ). Professora do Curso de Design, Departamento de Expressão Gráfica (EGR) da UFSC. Email: anaverpw@gmail.com.

${ }^{d}$ Doutor em Engenharia de Produção pela Universidade Federal de Santa Catarina (UFSC). Professor de Departamento em Ciência da Informação da Universidade Federal de Santa Catarina (UFSC). E-mail: wpwilliam@hotmail.com. 


\section{INTRODUÇÃO}

As bibliotecas universitárias (BUs) prestam serviços de informação para atender as necessidades da comunidade universitária, composta por docentes, discentes e técnicos administrativos. Contudo as necessidades tendem a mudar com frequência devido à evolução tecnológica, alterações curriculares, adequações de planejamento estratégico institucional, entre outros.

Os serviços informacionais, como dão suporte ao ensino, pesquisa e extensão, devem ser adequados continuamente para que a biblioteca permaneça em constante evolução, como os demais órgãos da universidade.

Embora as bibliotecas ofertem serviços clássicos e se atentem para as necessidades da comunidade universitária é salutar também conhecer o que tem sido estudado na área de Ciência da Informação (Cl) ou prestado por outras bibliotecas. Com isso, tem-se como objetivo, identificar os serviços inovadores que estão sendo publicados e prestados nas BUs brasileiras.

A relevância desse estudo está em conhecer o que tem sido tratado por pesquisadores da $\mathrm{Cl}$ e pelas BUs para que, ao adequar seus serviços às necessidades de sua comunidade, a BU o faça de uma forma que utilize de maneira eficaz o seu capital humano e os recursos disponibilizados pela instituição.

\section{METODOLOGIA}

O estudo caracterizou-se como uma pesquisa exploratória, descritiva, de cunho qualitativo, realizada através técnica de coleta de dados por meio de pesquisa bibliográfica e documental.

A característica exploratória se dá pela possibilidade de contato direto com os dados da pesquisa e descritiva pela possibilidade de descrever as características da população pesquisa. Tem cunho qualitativo pelos dados coletados não serem quantificados focando nas particularidades.

A pesquisa bibliográfica visa identificar na literatura o que está sendo publicado sobre os serviços inovadores e tendências em BU. O levantamento 
documental consistiu na identificação dos serviços prestados pelas bibliotecas para descobrir os serviços inovadores que já estão sendo prestados.

Para realizar a pesquisa das publicações que tratassem sobre a temática de inovação em BUs, fez-se a busca, no dia 13 de outubro de 2018, nas bases de dados Base de Dados em Ciência da Informação (BRAPCl, 2018) e no Scientific Electronic Library Online (SCIELO, 2018) que abrange uma coleção de periódicos científicos brasileiros, com os termos especificados a seguir.

Na Brapci pesquisou-se por: "inovação biblioteca* universitária*", sem aspas, tendo como resultado 15 artigos, verificando pelos termos no singular e no plural separadamente, sem o asterisco, obteve-se o retorno de 11 artigos em ambas as pesquisas, nenhum artigo além dos já recuperados.

$\mathrm{Na}$ SciELO pesquisou-se pelo termo "inovação" AND "biblioteca universitária", sem aspas, recuperando dois artigos e "inovação" AND "bibliotecas universitárias", sem aspas, recuperando um artigo. Os três artigos recuperados na SciELO já constavam nos resultados obtidos da busca na Brapci e, por isso manteve-se um total de 15 artigos recuperados (Quadro 1).

Os quatro artigos recuperados a mais na pesquisa inicial da Brapci foram marcados em negrito no Quadro 1 como forma de identificá-los. Com relação aos artigos recuperados na SciELO, contam em itálico os referentes a busca no plural e sublinhado àqueles obtidos pela pesquisa no singular.

\section{Quadro 1 - Pesquisa Brapci}

\begin{tabular}{|l|l|}
\hline AUTOR & Título \\
\hline Tarapanoff (1982) & A Biblioteca Universitária vista como uma organização social \\
\hline Andrade (1998) & $\begin{array}{l}\text { Mudanças e inovações: novo modelo de organização e gestão de } \\
\text { biblioteca acadêmica }\end{array}$ \\
\hline $\begin{array}{l}\text { Gomes Filho et al. } \\
\text { (2011) }\end{array}$ & $\begin{array}{l}\text { Desafio aos gestores de unidades de informação para implementar o } \\
\text { intraempreendedorismo e o empowerment }\end{array}$ \\
\hline Martins (2012) & $\begin{array}{l}\text { Gestão do conhecimento para serviços de informação: análise de } \\
\text { produtos e serviços inovadores em Bibliotecas Universitárias } \\
\text { Administração discursiva: uma nova perspectiva para as bibliotecas } \\
\text { universitárias brasileiras }\end{array}$ \\
\hline Dib e Lima (2013) & $\begin{array}{l}\text { Análise sociométrica da rede de relacionamento das bibliotecas que } \\
\text { Oliveira, Souza }\end{array}$ \\
\hline $\begin{array}{l}\text { Castro (2014)1 } \\
\text { Munstituem o Consórcio das Universidades Federais do Sul-Sudeste de }\end{array}$ \\
\hline $\begin{array}{l}\text { Juliani, Cavaglieri e e erais } \\
\text { Machado (2015) }\end{array}$ & $\begin{array}{l}\text { Design thinking como ferramenta para geração de inovação: um estudo } \\
\text { de caso da Biblioteca Universitária da UDESC }\end{array}$ \\
\hline Martins e Carmo & Criação da cadeia de suprimentos para e-books Supply chain for \\
\hline
\end{tabular}




\begin{tabular}{|l|l|}
\hline (2015) & creation e-books \\
\hline Juliani et al. (2016) & Design thinking como estratégia de inovação em bibliotecas \\
\hline $\begin{array}{l}\text { Lion e Miranda } \\
(2016)\end{array}$ & $\begin{array}{l}\text { Os estilos de funcionamento da liderança nas bibliotecas universitárias } \\
\text { do Sistema de Bibliotecas da Universidade Federal da Bahia } \\
\text { (SIBI/UFBA): um estudo sobre o Poder organizacional em Unidades de } \\
\text { Informação }\end{array}$ \\
\hline $\begin{array}{l}\text { Passos et al. } \\
\text { (2016) }\end{array}$ & $\begin{array}{l}\text { Inovação em serviços de informação: uma análise bibliométrica da } \\
\text { produção científica }\end{array}$ \\
\hline $\begin{array}{l}\text { Carvalho, Pontelo } \\
\text { e Gomes (2017) }\end{array}$ & $\begin{array}{l}\text { O Sistema de Bibliotecas da Universidade Federal de Minas Gerais: } 90 \\
\text { anos de um organismo em evolução }\end{array}$ \\
\hline Silva et al. (2017) & $\begin{array}{l}\text { A biblioteca universitária como um sistema adaptativo complexo (SAC): } \\
\text { variação }\end{array}$ \\
\hline $\begin{array}{l}\text { Murriel-Torrado e e } \\
\text { Gonçalves (2017) }\end{array}$ & $\begin{array}{l}\text { Youtube nas bibliotecas universitárias brasileiras: quem, como e para o } \\
\text { que é utilizado }\end{array}$ \\
\hline Saldanha (2017) & O que é nuvem? Cartas à biblioteca que vem \\
\hline
\end{tabular}

Fonte: Brapci (2018).

Nota ${ }^{1}$ : Artigos recuperados tanto na bases Brapci (2018) quanto na SciELO (2018)

Nota$^{2}$ : Artigo recuperado diretamente no site da revista devido a um erro no pdf da base de dados da Brapci.

Tendo em vista que a base da SciELO não permite delimitação por data, não foi feita a restrição em ambas bases de dados. Com isso, observa-se a recuperação de dois artigos muito antigos, com 37 e 21 anos de publicação, respectivamente para as duas primeiras menções no Quadro 1, os quais foram eliminados, permanecendo 13 artigos para análise do texto completo. Após a leitura observou-se que o artigo do Saldanha (2017) aborda temática em bibliotecas especializadas e também foi excluído, permanecendo 12 artigos para compor este estudo.

Para pesquisar os serviços prestados em BUs brasileiras, foi utilizado como filtro o ranking das melhores universidades (FOLHA DE SÃO PAULO, 2018). E, por considerar nesse estudo a inovação dos serviços, além das 10 melhores universidades, foram selecionadas também as 10 universidades melhores ranqueadas no quesito inovação (FOLHA DE SÃO PAULO, 2018).

As 10 universidades melhores ranqueadas no ano de 2018 são compostas por três estaduais em $1^{\circ}, 4^{\circ}$ e $8^{\circ}$ lugar respectivamente, sendo elas: Universidade de São Paulo (USP), Universidade Estadual de Campinas (Unicamp) e Universidade do Estadual Paulista (Unesp) e sete federais em $2^{\circ}$, $3^{\circ}, 5^{\circ}, 6^{\circ}, 7^{\circ}, 9^{\circ}$ e $10^{\circ}$ lugar respectivamente, a saber: Universidade Federal do Rio de Janeiro (UFRJ), Universidade Federal de Minas Gerais (UFMG), 
Universidade Federal do Rio Grande do Sul (UFRGS), Universidade Federal de Santa Catarina (UFSC), Universidade Federal do Paraná (UFPR), Universidade de Brasília (UnB), Universidade Federal de Pernambuco (UFPE).

Das dez primeiras universidades mais inovadoras, dentre as 196 melhores universidades ranqueadas no ano de 2018, sete delas são públicas, sendo duas estaduais (Unicamp, em $3^{\text {a }}$ lugar e USP na $8^{\text {a }}$ posição), cinco federais (UFRJ, UFPR, UFMG, Universidade Federal de Vitória (UFV), UFPE em $1^{\circ}, 2^{\circ}, 4^{\circ}, 5^{\circ}$ e $9^{\circ}$ lugar respectivamente) e três privadas (Universidade de Caxias do Sul (UCS) na 6o posição, Pontifícia Universidade Católica do Rio Grande do Sul (PUCRS) na $7^{a}$ e Pontifícia Universidade Católica do Rio de Janeiro (PUC-RIO) na 9․ Ressalta-se que tanto a UFPE quanto a PUC-RIO ficaram empatadas na 9 posição.

Das 20 universidades citadas, seis delas (Unicamp, USP, UFRJ, UFMG, UFPR e UFPE) aparecem tanto no ranqueamento das melhores universidades de 2018 como das universidades consideradas mais inovadoras. Portanto, a análise dos sites foi realizada em 14 universidades.

Antes de iniciar a análise dos artigos e dos serviços prestados nas BUs ranqueadas, contextualiza-se a seguir as temáticas abordadas nesse estudo.

\section{SERVIÇOS EM BIBLIOTECAS UNIVERSITÁRIAS}

Define-se BU como aquela que "[...] atende às necessidades de informação dos corpos docente, discente e administrativo, tanto para apoiar as atividades de ensino, quanto de pesquisa e extensão." (CUNHA; CAVALCANTI, 2008, p. 53).

As BUs prestam serviços visando o acesso e uso da comunidade acadêmica da Instituição de Ensino Superior a qual é vinculada a fim de satisfazer as necessidades.

O acervo para empréstimo domiciliar, empréstimo entre bibliotecas, comutação bibliográfica, reprografia, novas aquisições, catalogação na fonte/ficha catalográfica, visita orientada, orientação ao usuário para recuperação de informação, acesso às bases de dados, 
treinamento/capacitação de usuários, normalização de trabalhos técnicocientíficos, assuntos relacionados com o mercado editorial, são os principais serviços prestados nas BUs brasileiras, segundo a pesquisa de Amboni (2002).

Com relação ao perfil de uso das bibliotecas contemporâneas, ou seja, atuais e modernas, Valentim (2017) aponta como sendo um ambiente customizado para interação, cultura e lazer, que atende diferentes públicos e oferece apoio da educação formal e informal.

Considerando que as necessidades da comunidade acadêmica tendem a mudar constantemente e ponderando as novas tecnologias, alterações de currículos dos cursos, criações de novos cursos, inserções de novos projetos de pesquisa e extensão universitária, entre outras, tanto a universidade, quanto a BU precisam se adequar, inovando com frequência.

\section{SERVIÇOS INOVADORES E TENDÊNCIAS EM BIBLIOTECAS}

Consta no Manual de Oslo (1997, p. 55) que a inovação é:

[...] a implementação de um produto (bem ou serviço) novo ou significativamente melhorado, ou um processo, ou um novo método de marketing, ou um novo método organizacional nas práticas de negócios, na organização do local de trabalho ou nas relações externas.

Os serviços prestados nas BUs são, em sua maior parte, convergentes (ROSSI, 2012) e continuamente devem ser atualizados acompanhando as tendências e discussões para propiciar a inovação nos serviços das bibliotecas.

Enfrenta-se uma crise no país e sabe-se da dificuldade financeira que as universidades têm enfrentado. Saeteren (2005) relata que sem dinheiro podese optar por "sentar e chorar" ou lutar e utilizar a imaginação e a criatividade para buscar novas soluções, sendo, a inovação, uma das alternativas.

No mapeamento das tendências relevantes para as bibliotecas, realizado pelo Center for the Future of Libraries da American Library Association (ALA, 2014), constataram: impacto coletivo; compartilhamento da economia; dados em todo lugar; colaboração criativa; aprendizagem conectada; brinquedos conectados; controle de voz; drones; Internet das 
coisas; robôs; realidade virtual; nativos digitais; aprendizagem invertida etc.

Acrescido a isso, a Association of College \& Research Libraries (ACRL, 2018) publica as principais tendências para as BUs, dentre algumas apontam:

a) editor e fornecedores têm prestado mais atenção à infraestrutura de publicação e aos elementos da comunicação acadêmica, prestando um serviço completo e simplificado para a pesquisa acadêmica;

b) notícias falsas e alfabetização informacional: importância em considerar a complexidade de notícias falsas e a alfabetização informacional para o combate a elas;

c) bibliotecários como parceiros colaborativos nos projetos em vez de somente provedores de serviços para projetos;

d) conscientização do valor da biblioteca para apoiar no desenvolvimento do corpo docente e do curso;

e) análise de aprendizado, de coleta de dados e preocupações éticas de privacidade do usuário; $e$,

f) aquisição de conjuntos de dados de pesquisa, dedicação à mineração e melhoria na formação da ciência de dados.

Em 2016, a Association of College \& Research Libraries (ACRL, 2016) já havia publicado como tendências: serviços de dados de pesquisa; políticas de dados e gestão de dados de pesquisa; centros de pesquisas digitais; fusões de provedores de conteúdo/concentração em plataformas de conteúdo; altimetria.

Fernández Marcial (2016) propõe que a inovação seja incorporada ao gerenciamento de bibliotecas para a projeção e implementação de serviços de informação úteis aos usuários, a partir das exigências e requisitos balizados por eles. A autora apresenta várias iniciativas inovadoras como: aproximação com os usuários e mudando-se para onde eles estão; inovação no empréstimo; incorporação e utilização das tecnologias como aliada; promoção à cultura de colaboração e aprendizagem compartilhada; outros destaques, como gestão do conhecimento; crowdfunding, entre outros.

Modesto (2018) aponta o learning commons como exemplo inovador, e apresenta a internet das coisas, o gerenciamento de dados de pesquisa, a biblioteca das coisas, os espaços colaborativos, o compartilhamento de dados. 
Além destes, passa-se a seguir a analisar os dados coletados nesta pesquisa.

\section{SERVIÇOS INOVADORES PRESTADOS EM BIBLIOTECA UNIVERSITÁRIA BRASILEIRA}

Aponta-se, como um estudo preliminar sobre os serviços inovadores prestados em BUs, recuperados em bases de dados nacionais e coletados nos sites das BUs brasileiras.

\subsection{Pesquisa nas Bases de Dados Brasileiras}

Por meio da pesquisa realizada nas bases de dados Brapci (2018) e SciELO (2018) recuperou-se 12 artigos, a partir da década de 2010, que versassem sobre inovação em $\mathrm{BU}$ os quais serão relatados a seguir em ordem cronológica e alfabética de sobrenome do autor.

Gomes Filho et al. (2011) mencionaram que a gestão a partir do empreendedorismo interno está associada à inovação por estimulá-la, dando aos colaboradores recursos e independência para inovar dentro da organização e apontaram que empowerment é a tecnologia de gestão de pessoas empregada para gerenciar o poder dentro das organizações.

Os autores constataram uma predominância de $60 \%$ de características inovadoras na amostra da biblioteca estudada na região sul do Brasil, o que implica dizer que existem elementos propícios ao desenvolvimento do intraempreendedorismo. Acrescentam que possui um clima favorável para a implementação do empowerment, tendo como desafio para o gestor dominar as técnicas de aplicação e a promoção de cursos para o desenvolvimento das características empreendedoras, a fim de praticar a administração empreendedora e o espírito empreendedor no quadro de colaboradores (GOMES FILHO et al., 2011).

Embora o estudo não consiga identificar se a pessoa será um empreendedor de sucesso, é interessante conhecer as características dos 
colaboradores que estão atuando nas bibliotecas, para que o gestor possa dar o poder para o colaborador desenvolver atividades e estratégias que elevem os serviços ofertados pela biblioteca.

Martins (2012) verificou que cada vez mais as instituições utilizam-se de redes sociais, como ferramenta de GC, para melhorar o relacionamento com o usuário. Observou ainda que as bibliotecas inovaram ao oferecer: entrega domiciliar de obras; central de atendimento telefônico; atendimento online (chat); negociação de multa com desconto e pagamento do restante do valor com livros novos; aviso por e-mail de devolução, empréstimo em atraso e reserva liberada; terminais de autodevolução e autoempréstimo; conversa por MSN com o setor de aquisições; empréstimo de sacolas para transporte de materiais. $\mathrm{O}$ autor concluiu que:

[...] várias instituições criaram serviços únicos para atender as necessidades dos seus usuários, colocando-se à frente em termos de competitividade e inovação, porque muitos desses serviços foram criados baseados na gestão do conhecimento interno (colaboradores) e externo (usuários). (MARTINS, 2012, p. 27).

Embora relatem na literatura já possuírem nas BUs o atendimento via telefone e o envio automático de e-mail pelo sistema nas principais transações, outros serviços apontados nesse estudo ainda não são encontrados na maior parte das bibliotecas, mesmo nos dias atuais. Fernández Marcial (2016) corrobora com o estudo de Martins (2012) quando indica a incorporação e utilização das tecnologias como aliadas da inovação.

Dib e Lima (2013) identificaram que há predominância de racionalidade instrumental nas formas de administração utilizadas pelas BUs brasileiras pesquisadas e sugeriram a administração discursiva por possibilitar a interação entre as pessoas e a reflexão coletiva, além de perceber e entender os problemas práticos e de buscar soluções. Apresentaram como vantajosa, pois:

[...] possibilita a interação e a colaboração entre as pessoas; viabiliza o diálogo, a autonomia e a liberdade; assegura 0 compromisso de todos com as decisões e com as escolhas adotadas; democratiza o processo de administração da biblioteca; promove o desenvolvimento, proporcionando melhores resultados para a biblioteca, e, por conseguinte, para a universidade, propiciando 0 bem-estar pessoal e 0 
aprendizado contínuo de seus membros (DIB; LIMA, 2013, p. 114).

Esse estudo é relevante porque as formas de administrar as bibliotecas podem influenciar significativamente os serviços e produtos ofertados, da mesma forma que a interação, amplamente incentivada na administração discursiva, promove colaboração e condições melhores para que os colaboradores inovem continuamente.

Oliveira, Souza e Castro (2014, p. 130-131) tinham por objetivo:

[...] identificar a estrutura da rede de relacionamentos das Bibliotecas que constituem o Consórcio das Universidades Federais do Sul-Sudeste de Minas Gerais e verificar quais instituições se mostram mais centrais na estrutura de relacionamentos.

Como resultados identificaram que a Universidade Federal de Juiz de Fora (UFJF) e a Universidade Federal de Viçosa (UFV) possuíam grande centralidade, representando uma condição favorável para a busca e trocas de informações e um maior grau de flexibilidade e inovação. No lado oposto encontram-se as Universidades Federais de São João Del-Rei (UFSJ) e de Itajubá (UNIFEI) "[...] em posições periféricas, não interagindo de forma intensiva com as demais instituições da rede.", o que ocasiona "[...] a perda de benefícios e novas oportunidades." (OLIVEIRA; SOUZA; CASTRO, 2014, p. 131).

A partir desse estudo, pode-se perceber, em nível de grupo, como as instituições podem se complementar e crescer juntas, gerando inovações e competitividade coletiva ou tentar se desenvolver de forma isolada. Cabe ressaltar que a UFV foi listada em 15 lugar entre as melhores universidades no ranking, segundo a Folha de São Paulo (2018), e como 5á das universidades mais inovadoras.

Juliani, Cavaglieri e Machado (2015) abordaram o uso das técnicas do design thinking como ferramenta de interação e aproximação entre os colaboradores, comunidade e usuários para geração de serviços inovadores para a Biblioteca da Universidade do Estado de Santa Catarina (BU/UDESC). Esse conceito é trazido como ferramenta para resolver problemas, descobrir os desejos e necessidades pessoais, focando prioritariamente nas pessoas. 
As principais ideias para atender as necessidades da comunidade pesquisada foram: sinalização da biblioteca; serviço de informação turística; grupos específicos de interesse; e, papa livros. Com base nisso, os autores trabalharam na descrição de implementação de um serviço para usuários com deficiência (JULIANI; CAVAGLIERI; MACHADO, 2015).

Os autores trazem uma técnica interessante para a identificação das necessidades específicas da comunidade para subsidiar a implementação e ajuste de serviços das $\mathrm{BU}$, diferente da que normalmente é praticada, o estudo de usuários, que tende a ser amplo, quantitativo e focado nos usuários que já utilizam a biblioteca.

Martins e Carmo (2015) propõem a introdução da cadeia de gerenciamento de suprimentos para e-books como uma inovação incremental no processo de formação e desenvolvimento de coleções. Como resultado terse-ia uma plataforma única para os e-books expandindo o acesso a esses materiais pelos usuários de todo o Brasil. A concepção ficaria a cargo do governo federal em conjunto com bibliotecários das BUs, em parceria com comitê editorial a fim de baratear o custo de produção, comercialização, distribuição e disseminação, e reduzir os desnivelamentos de acesso do país com a democratização da leitura.

A proposta dos autores assemelha-se ao que já é feito pelo Portal de Periódicos da CAPES, focado na disseminação de bases de dados de periódicos. Uma única plataforma para disponibilização de livros eletrônicos convergiria com o que a Association of College \& Research Libraries (2016) propõe "fusão de provedores de conteúdo/concentração em plataformas de conteúdo", a fim de facilitar a busca e recuperação das informações por parte dos usuários.

Juliani et al. (2016) empregaram as técnicas e processos do design thinking, que compreende a imersão, análise e síntese, ideação e prototipação. A coleta de dados para geração de ideias envolveu entrevista com alunos, professores e servidores da Udesc, empresários e a comunidade do bairro Itacorubi. 
Os autores propuseram a prototipação de inovação incremental na sinalização da biblioteca central da Udesc. Sugeriram o uso de sinalização de piso com cores diferenciadas; adoção de uma identidade gráfica e visual para os assuntos do acervo; inclusão das capas de livros no catálogo; adoção de mapas com layout da biblioteca em todos os andares; e, uso de QRCode para identificação das estantes no acervo.

A sinalização traz autonomia para o usuário no deslocamento e busca da informação, mas seria interessante ter previsto também, com base na demanda levantada pelo estudo de Juliani, Cavaglieri e Machado (2015), na mesma instituição e metodologia, a sinalização de piso tátil, mapa tátil e placas de sinalização em alto relevo para os usuários com deficiência.

Lion e Miranda (2016) apresentam os estilos de liderança e o resultado da aplicação de questionário com quatro bibliotecários chefes das quatro maiores BUs do Sistema de Bibliotecas da Universidade Federal da Bahia. Concluíram que os bibliotecários chefes podem reunir habilidades complementares em suas equipes para alcançar desempenhos superiores compartilhando informações, responsabilidades e colaboração que gerem confiança da equipe no líder. Alertam para que seja desenvolvido o autoconhecimento, a percepção do ambiente externo, melhoria dos relacionamentos e da capacidade criativa e de inovação.

Da mesma maneira que foi apontada anteriormente, a forma de administrar influencia as pessoas, produtos e serviços ofertados. E, como na administração discursiva, trazida por Dib e Lima (2013), a promoção da interação e da colaboração entre as pessoas democratiza o processo administrativo, assegura o compromisso da equipe, promove melhores resultados para a biblioteca e o bem-estar para as pessoas.

Passos et al. (2016) mapearam a produção científica por meio da análise bibliométrica de 118 documentos recuperados em setembro de 2015 na Web of Science sobre inovação em serviços de informação com foco em bibliotecas.

Obtiveram como resultado que o periódico que mais publica sobre a temática é o Library Journal; que a maior parte dos artigos foram publicados 
nos Estados Unidos da América; as palavras-chave que mais apareceram nos artigos recuperados foram "information" e "public"; dos dez artigos mais citados, oito tratam de estudos exploratórios e os outros dois são estudos teóricos; dos dez artigos mais citados seis foram aplicados em BUs. Concluíram que cada estudo analisa uma vertente diferente da inovação e, para prover diretrizes a fim de criar ou reestruturar um serviço de informação inovador só seria possível analisando o conjunto dos estudos (PASSOS et al., 2016).

Os autores identificaram, da mesma forma que este estudo, diferentes vertentes da inovação nos serviços inovadores em BUs brasileiras, que, somente no embasamento dos estudos de forma conjunta e aprofundada, poderiam subsidiar alterações substanciais dos serviços hoje prestados.

Carvalho, Pontelo e Gomes (2017, p. 137) apresentaram várias ações para inovar os produtos e serviços que têm sido realizadas pelas bibliotecas da UFMG, como:

[...] apoio às bibliotecas polos da educação à distância, renovação de espaços físicos, oferecimento de novos serviços aos pesquisadores, grupos de trabalho para introduzir os ebooks no acervo geral da universidade, implementação de políticas para criação de repositórios e acesso aberto, suporte aos usuários do Portal de Periódicos da Capes, treinamento de pesquisadores para uso das ferramentas de busca, manutenção da Biblioteca Digital da UFMG, promoção da referência digital, uso de ferramentas da Web 2.0, busca de parcerias institucionais, apoio à implementação do Portal de Periódicos da UFMG; cooperação com projetos de pesquisa e com a Diretoria de Governança Informacional da UFMG.

Os autores acrescentam que a biblioteca tem o suporte interno da Divisão de Inovação e Gestão Tecnológica que realiza a disponibilização da produção científica dos programas de pós-graduação da universidade, que otimiza e intermedeia as demandas da comunidade e o uso dos recursos para o acesso ao Portal de Periódicos da Capes e que auxilia e assessora as bibliotecas dos polos da Universidade Aberta do Brasil que tenham envolvimento com a UFMG (CARVALHO; PONTELO; GOMES, 2017).

Chama-se a atenção que a UFMG é a $3^{\text {a }}$ melhor universidade e $4^{a}$ mais inovadora, segundo a Folha de São Paulo (2018) e que, para isso, um movimento em prol a causa, provavelmente foi feito por todos os órgãos da 
universidade e, neste trabalho constata-se a preocupação com a ocupação de um lugar central no ensino-aprendizagem, produção e comunicação desta BU.

Silva et al. (2017) identificaram as principais modificações que aconteceram nas bibliotecas da UFSC e o que influenciaram essas mudanças, a partir do elemento variação do Framework GC@BU e da concepção da biblioteca como um Sistema Adaptativo Complexo.

As mudanças mais significativas foram oportunizadas pelos: avanços da tecnologia/novas demandas; expansão dos serviços; usuário autônomo; evasão do conhecimento; necessidade de novas competências profissionais e de ampliação de infraestrutura; acessibilidade; biblioteca como espaço de aprendizagem, espaço cultural e, como ponto de encontro. E identificaram como influenciadores dessas mudanças: tecnologia, outras instituições, educação continuada dos servidores, perfil dos servidores, normas/legislação, perfil do usuário, fornecedores e demandas internas (SILVA et al., 2017).

A implantação da gestão do conhecimento e a percepção da biblioteca como um sistema adaptativo complexo promovem, como relatado por Fernández Marcial (2016) que a inovação seja incorporada ao gerenciamento de bibliotecas, o que irá refletir diretamente nos produtos e serviços ofertados.

Murriel-Torrado e Gonçalves (2017) propuseram a identificação de como o YouTube era usado nas 50 principais BUs mais reconhecidas do Brasil. Verificaram que apenas dez apresentaram um link para o canal, destas, algumas utilizavam a plataforma como um armazém de conteúdo audiovisual ou como um vídeo tutorial para algum assunto. Os autores relataram que "os vídeos são um complemento ideal dentro da estratégia de marketing de relacionamento mediado pelas mídias sociais" e que podem ser utilizados para:

[...] gravação de breves aulas expositivas de assuntos de interesse para os usuários; registro de eventos que aconteçam na biblioteca ou na universidade; explicações dos bibliotecários ou dos próprios usuários sobre como usar os serviços da biblioteca; apresentação de procedimentos da universidade: como conseguir a carteira de estudante, como criar um email institucional, etc.

Não se achou nenhuma biblioteca que utilizasse YouTube ao vivo (Live), pois esta é uma interessante possibilidade, por exemplo, para transmitir palestras (MURRIEL-TORRADO; 
GONÇALVES, 2017, p. 11).

Novamente Fernández Marcial (2016) colabora quando aponta que a biblioteca tem que se aproximar dos usuários mudando-se para onde eles estão e, o uso dos vídeos, acaba sendo a unificação da prestação de serviço e a tecnologia digital. Além disso, alinha-se com o que Saeteren (2005) preconiza da busca de novas soluções, mesmo sem dinheiro, tendo em vista que o YouTube é gratuito tanto para a publicação, como para a exibição dos vídeos e atende, de certa forma, as demandas dos usuários digitais.

Esses foram os artigos recuperados e analisados e, de forma a ampliar o estudo, passa-se a analisar os serviços que efetivamente estão sendo prestados nas BUs brasileiras com base em seus respectivos sites.

\subsection{Pesquisa nos Serviços Informacionais Prestados em Universidades BRASILEIRAS}

Em algumas das 14 universidades analisadas, entre as 10 melhores universidades brasileiras e as 10 melhores pontuadas no quesito inovação (FOLHA DE SÃO PAULO, 2018), teve-se que realizar a pesquisa em mais de uma biblioteca da instituição, devido a elas não possuírem um sistema de bibliotecas ou um site único para ele, como foi o caso da Unesp (2018), UFV (2018a; 2018b; 2018c), UnB (2018).

As bibliotecas da UFPE (2018) e da UFRGS (2018) possuem um site para o sistema de bibliotecas, mas também disponibilizam sites próprios de cada setorial com os serviços prestados de forma bem descritiva e, por isso verificou-se tanto o site do sistema como individual das bibliotecas para complementação.

Para uma tentativa de aprofundamento, ampliou-se a pesquisa nos sites das bibliotecas das instituições para além da menção de "Produtos e serviços" porque alguns serviços são dispostos em links separados. Com isso, alguns produtos e serviços podem ter passado despercebidos, devido à quantidade de informações das páginas e falta de concentração de informações em links específicos.

Como exemplo, na Unesp (2018) o Laboratório de Suporte às Carreiras 
(LabCar) é uma iniciativa de uma das 33 bibliotecas, as quais foram analisadas separadamente, e está no menu "Sobre". O LabCar tem por objetivo oferecer fundamentos para discussão sobre trajetória profissional, conhecimento do mercado de trabalho, ideias de carreira e empreendedorismo, é um programa com foco no desenvolvimento de negócios inovadores e a integração de diferentes atores do ecossistema inovador.

A UnB (2019) divulgou na Comissão Brasileira de Bibliotecas Universitárias (CBBU) em setembro de 2018 o Espaço POP, que ainda não constava na lista de serviços. Este serviço proporciona oficinas e debates; estimula o uso de jogos de tabuleiro; disponibiliza local lúdico para leitura, entretenimento e socialização entre usuários.

Observou-se que os serviços das BUs continuam convergentes, como apontado por Amboni (2002), na pesquisa dos principais serviços prestados pelas bibliotecas federais brasileiras e por Rossi (2012) no estudo realizado nas BUs em Santa Catarina.

Dentre os 82 serviços e produtos identificados nas 14 instituições analisadas, destacam-se: acesso à internet; conexão remota; acesso ao acervo/catálogo online; consulta local; empréstimo; devolução; renovação; reserva; comutação bibliográfica; empréstimo entre bibliotecas de outras instituições; empréstimo interbibliotecas; ficha catalográfica; portal de periódicos institucional; repositório institucional; indicações de bases de dados, de livros eletrônicos e de periódicos gerais; menções de espaços disponibilizados para diversas demandas; orientações para solicitação de ISBN e de ISSN; orientação de normas para publicação; capacitações/treinamentos; orientações individuais e em grupos; e, visitas orientadas.

Contudo, algumas bibliotecas tiveram destaque com serviços que podem se tornar referência para as demais bibliotecas por serem inovadores. Iniciando com a motivação de Saeteren (2005) para usar a criatividade e a imaginação enquanto não se tem verba para investimento, os serviços de consultoria, orientação e capacitação (Quadro 2) são uma estratégia e, tornam-se serviços inovadores quando vinculados às temáticas crescentes no interesse dos usuários, como: 
Quadro 2 - Serviços de consultoria, orientação e/ou capacitação dos usuários

\begin{tabular}{|c|c|c|c|}
\hline Serviço & $\begin{array}{c}\text { Melhores } \\
\text { universidades }\end{array}$ & $\begin{array}{c}\text { Melhores } \\
\text { universidades e } \\
\text { mais inovadoras }\end{array}$ & $\begin{array}{c}\text { Mais } \\
\text { inovadoras }\end{array}$ \\
\hline Gerenciadores de referências & $\begin{array}{c}\text { UFRGS, } \\
\text { UFSC e Unesp }\end{array}$ & USP & $\begin{array}{l}\text { PUC-RIO, } \\
\text { PUCRS e UCS }\end{array}$ \\
\hline $\begin{array}{l}\text { Avaliação científica, Direitos autorais, } \\
\text { Métricas, Fator de Impacto e Índice H }\end{array}$ & Unesp & USP & PUCRS e UCS \\
\hline Patente & - & - & UCS \\
\hline $\begin{array}{l}\text { Detecção de plágio* (alguns com } \\
\text { software free) }\end{array}$ & $\begin{array}{l}\text { UFRGS e } \\
\text { UFSC }\end{array}$ & UFRJ & PUCRS \\
\hline $\begin{array}{l}\text { Autoarquivamento de trabalhos de } \\
\text { conclusão de curso** }\end{array}$ & Unesp & - & - \\
\hline
\end{tabular}

Fonte: Dados coletados pelo autor no site das bibliotecas das instituições (PUC-RIO, 2018; PUCRS, 2018; UCS, 2018; USP, 2018; UNESP, 2018; UFSC, 2018; UFRGS, 2018).

Nota*: Alguns indicam softwares free e a UFSC possui uma Comissão de "Plágio e má conduta em pesquisa", porém ainda não é um serviço ofertado ao usuário.

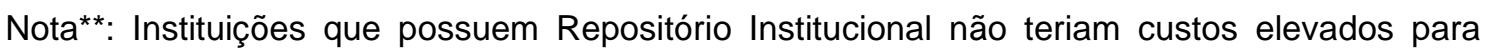
customizar esse serviço.

As ferramentas de busca integrada seriam um exemplo da tendência indicada pela Association of College \& Research Libraries $(2016 ; 2018)$ dos editores e fornecedores prestando serviços mais completos e simples para os usuários e tem sido ofertada pelas melhores universidades (UNESP, 2018; UFSC, 2018) e nas mais inovadoras também (PUC-RIO, 2018; PUCRS, 2018).

Os serviços de dados de pesquisa e políticas de dados e gestão de dados de pesquisa citados pela Association of College \& Research Libraries (2016) estão iniciando seus serviços na Unesp (2018) (entre as melhores universidades) com o "Ponto de apoio FAPESP" e com os serviços de "Dados de Pesquisa", que inclui Plano de Gestão de Dados, Repositório de Dados, Como organizar os dados de pesquisa, Como citar os dados de pesquisa, os quais estão sendo ofertados pela USP (2018) (entre as melhores e mais inovadoras universidades).

Embora não conste como serviços prestados, a UFSC (2018) (que está entre as melhores universidades) possui uma comissão de Concepção do Serviço de Suporte à Pesquisa e Gerenciamento de Dados, desde 2016, e promoveu um Seminário Nacional de Suporte à Pesquisa e Gestão de Dados Científicos em 2017.

Corroborando com Fernández Marcial (2016) no quesito de implementar 
serviços e produtos de informação úteis, aproximando-os dos usuários, a disponibilização 24 horas por dia/7 dias por semana das bases de dados, livros eletrônicos, periódicos gerais, portal de periódicos institucional e repositório institucional são prestados por todas as instituições pesquisadas, embora esses dois últimos algumas vezes não mencionados, com evidência, nos sites das bibliotecas com evidência.

Além desses, o atendimento por 24 horas, a promoção de ações culturais e exposições colaboram na integração do usuário à biblioteca, são momentos de lazer que eles podem aproveitar em meio à carga de estudo diário. Fernández Marcial (2016) também acrescenta a incorporação das tecnologias, e destaca-se: Aplicativos para dispositivos móveis, Atendimento online, Digitalização de documentos, Empréstimo de equipamentos e similares, Geração automática de Ficha Catalográfica (Quadro 3).

\section{Quadro 3 - Serviços e produtos de informação útil e próximo dos usuários/Incorporando tecnologias}

\begin{tabular}{|l|c|c|c|}
\hline \multicolumn{1}{|c|}{ Serviço } & $\begin{array}{c}\text { Melhores } \\
\text { universidades }\end{array}$ & $\begin{array}{c}\text { Melhores } \\
\text { universidades e } \\
\text { mais inovadoras }\end{array}$ & $\begin{array}{c}\text { Mais } \\
\text { inovadoras }\end{array}$ \\
\hline Biblioteca 24 horas & - & UFMG* & - \\
\hline Ações culturais & UFSC e UnB & UFRJ e Unicamp & - \\
\hline Exposição & $\begin{array}{c}\text { UFRGS, UFSC e } \\
\text { Unesp }\end{array}$ & UFMG e UFRJ & - \\
\hline $\begin{array}{l}\text { Aplicativos para dispositivos } \\
\text { móveis** }\end{array}$ & $\begin{array}{c}\text { Unesp e UFRGS } \\
\text { Atendimento online }\end{array}$ & $\begin{array}{l}\text { Unicamp e USP } \\
\text { UFRGS, UFSC e } \\
\text { Unesp UnB }\end{array}$ & $\begin{array}{c}\text { PUC-RIO e } \\
\text { PURS }\end{array}$ \\
\hline Digitalização de documentos & $\begin{array}{c}\text { UFRG, UFSC, UnB } \\
\text { e Unesp }\end{array}$ & UFPR e UFRJ & $\begin{array}{c}\text { PUC- } \\
\text { RIO*** }\end{array}$ \\
\hline $\begin{array}{l}\text { Empréstimo de equipamentos } \\
\text { de notebooks e similares }\end{array}$ & $\begin{array}{c}\text { UF*** UFS, UFSC, UnB } \\
\text { e Unesp }\end{array}$ & UFPR e UFRJ & PUCRS \\
\hline $\begin{array}{l}\text { Geração automática de Ficha } \\
\text { Catalográfica }\end{array}$ & UFRGS e UFSC & UFRJ & PUCRS \\
\hline
\end{tabular}

Fonte: Dados coletados pelo autor no site das bibliotecas das instituições (UFMG, 2018; UFRJ, 2018; UNICAMP, 2018; USP, 2018; UFPR, 2018; PUC-RJ, 2018; PUCRS, 2018; UFSC, 2018; UNB, 2018; UFRGS, 2018; UNESP, 2018).

Nota*: Duas bibliotecas da UFMG ficam abertas 24 horas por dia com a oferta restrita de serviços.

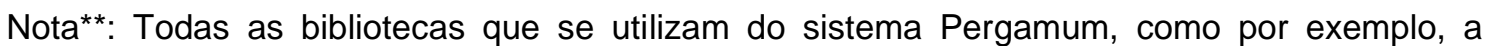
UFSC, embora não evidencie em seu site, se encontra disponível para o usuário.

Nota**: A UnB está atendendo via Whatsapp e a PUC-RIO por meio de chat online. Embora não tenham evidenciado, a maior parte das bibliotecas atende por meio do preenchimento de formulários no site ou por e-mail. 
Nota $^{\star \star * *}$ : Além de notebooks a UFRGS empresta e-Reader, a UFSC empresta tablets, calculadora, carregador de celular, adaptador e a UFRJ empresta calculadora e Ipad.

O serviço de Identificador do pesquisador, normalmente mencionado pelo ORCID, é ofertado pela Unesp (2018) (considerada uma das melhores universidades), Unicamp (2018) e USP (2018) (consideradas melhores e mais inovadoras) e PUCRS (2018) (considerada uma das mais inovadoras).

Outros serviços, que embora não descritos explicitamente pelas bibliotecas, podem estar sendo pensados/ofertados são: a Aprendizagem conectada (American Library Association, 2014) alcançada com a educação à distância; e, a Aprendizagem invertida motivada nas capacitações e atendimentos individualizados.

As indicações de tendências da American Library Association (2014) que não foram localizadas nos sites das bibliotecas pesquisadas referem-se às atividades que envolvem internet das coisas, drones, robôs, controle de voz ou realidade virtual, e outras tecnologias mais avançadas.

Contudo, Carvalho, Pontelo e Gomes (2018) apontam que em agosto de 2017 foi lançado edital de chamada interna, denominado "Programa transversal de apoio às bibliotecas da UFMG - internet das coisas" que tem por objetivo promover a criação de um Espaço Internet das Coisas na BU/UFMG com vistas à: melhoria da infraestrutura do ensino, pesquisa e extensão; estrutura da $\mathrm{BU}$; atuação dos recursos humanos da $\mathrm{BU}$; fomento da criatividade; inventividade; integração do profissional formado e o atuante na instituição; e, desenvolvimento da gestão da informação.

O serviço de consultoria, orientação e/ou capacitação são ações sem custos elevados e necessidade de tecnologias extras, para isso seria necessário o treinamento dos profissionais das instituições. No quesito ações culturais e exposições são atividades que podem ser realizadas em parceria com outras instituições ou departamentos, com custos mínimos ou sem custo.

Para a digitalização de documentos e empréstimo de equipamentos precisa-se adquiri-los e prover a manutenção dos mesmos. Para a utilização da busca integrada, serviço de identificador do pesquisador, utilização de dispositivos móveis e geração automática de ficha catalográfica são 
necessários o desenvolvimento de ferramentas específicas ou contratação de alguma disponível no mercado. Da mesma forma para a realização de atendimento online.

Com relação aos serviços de dados de pesquisa e políticas de dados e gestão de dados de pesquisa, é possível a realização de algumas ações de orientação aos pesquisadores por meio de treinamento prévio dos profissionais da $\mathrm{BU}$, contudo o desenvolvimento completo desse serviço necessita do aprofundamento de estudos de Repositório de Dados mais adequado para a Instituição, desenvolvimento ou contratação e customização para melhor atender à comunidade.

Por fim, as tendências mais tecnológicas como a utilização da internet das coisas, drones ou robôs, controle de voz ou realidade virtual, entre outras tecnologias poderiam ser desenvolvidas em parceria com os laboratórios tecnológicos da instituição ou até mesmo criando um novo serviço na BU, o Makerspace onde os usuários teriam oportunidade de desenvolver seus equipamentos unificando o conhecimento à prática.

É provável que mais iniciativas estejam ocorrendo nas bibliotecas brasileiras ou sendo elaboradas pelos pesquisadores e que, em breve, surgirão outros construtos para analisar, propiciando assim a constante reformulação dos produtos e serviços oferecidos nas BUs brasileiras.

\section{CONSIDERAÇÕES FINAIS}

Observa-se, perante o total de serviços disponibilizados pelas BUs estudadas, que os serviços inovadores ainda são em números reduzidos e disperso entre as BUs, não refletindo em todas as universidades consideradas mais inovadoras pela Folha de São Paulo (2018).

Verificou-se que as universidades mais inovadoras desenvolvem programas específicos para inovação e focam bastante em pesquisas, o que deve contribuir para a geração de novos produtos e patentes vinculados a elas.

Ressalta-se que a maior parte dos estudos recuperados não aborda a inovação diretamente, mas sim um ou outro ponto que motiva a inovação. Nos 
estudos identificou-se modelos de gestão, como empowerment, administração discursiva, liderança e aplicação da gestão do conhecimento aliada a identificação da BU como um sistema adaptativo complexo, trazidos respectivamente por Gomes Filho et al. (2011), Dib e Lima (2013), Lion e Miranda (2016) e Silva et al. (2017), os quais valorizam o colaborador e propiciam o desenvolvimento de produtos e serviços inovadores.

Oliveira, Souza e Castro (2014) trazem a colaboração entre instituições como forma de inovação e desenvolvimento conjunto. Juliani, Cavaglieri e Machado (2015) e Juliani et al. (2016) abordam a técnica do design thinking como ferramenta para geração de serviços inovadores.

Martins (2012) trouxe serviços inovadores que estão sendo ofertados nas BUs estudadas e Carvalho, Pontelo e Gomes (2017), nas bibliotecas da UFMG, os quais percebe-se em sua maior parte, que também estão sendo prestados pelas BUs pesquisadas nesse estudo. Martins e Carmo (2015) trouxeram um serviço inovador específico, a criação de uma plataforma única para disponibilização dos livros eletrônicos e Murriel-Torrado e Gonçalves (2017) propuseram o uso do YouTube para diversas finalidades na biblioteca.

Por fim, Passos et al. (2016) realizaram um mapeamento da produção científica sobre inovação em serviços de informação na Web of Science que teve resultado muito semelhante ao desta pesquisa, que, no caso da literatura levantada, as vertentes de abordagem da inovação para serviços inovadores em BUs brasileiras são dispersos e somente pelo estudo aprofundado e de um conjunto de estudos, poderiam subsidiar alterações substanciais ou exclusões de serviços tradicionais hoje prestados nas BUs.

Conclui-se que as BUs estão promovendo inovação em seus serviços informacionais e, para isso, não é necessário grandes investimentos ou possuir tecnologia de ponta. É possível o desenvolvimento de inovação por meio de parcerias, novas ideias, treinamento e colaboração da equipe, desenvolvimento e/ou aquisição de ferramentas e equipamentos. 


\section{REFERÊNCIAS}

AMBONI, Narcisa de Fátima. Qualidade em serviços: dimensões para orientação e avaliação das bibliotecas universitárias federais brasileiras. 2002. 228 f. Tese (Doutorado em Engenharia de Produção) - Universidade Federal de Santa Catarina, Florianópolis, 2002.

AMERICAN LIBRARY ASSOCIATION (ALA). Center for the Future of Libraries. Library of the Future. Trends. Chicago, Aug. 2014.

ANDRADE, Maria Terezinha Dias de; CUENCA, Angela Maria Belloni; SADI, Benedita Silveira Campos; CAMARGO, Cibele Araújo; ABDALLA, Eidi Raquel Franco; HUSSEIN, Francis Sierra; DAMICO, José Sergio; ALVAREZ, Maria do Carmo Avamilano; CRESTANA, Maria Fazzaneli; SANTOS, Mirian; ELEUTÉRIO, Sônia Garcia Gomes; BARONE, Sônia Regina de Mesquita. Mudanças e inovações: novo modelo de organização e gestão de biblioteca acadêmica. Ciência da Informação, Brasília, n. 3, v. 27, p. 311-318, set./dez. 1998.

ASSOCIATION OF COLLEGE \& RESEARCH LIBRARIES (ACRL). 2016 top trends in academic libraries: a review of the trends and issues affecting academic libraries in higher education. College \& Research Libraries News, Chicago, v. 77, n. 6, p. 274-281, June 2016.

ASSOCIATION OF COLLEGE \& RESEARCH LIBRARIES (ACRL). 2018 top trends in academic libraries: a review of the trends and issues affecting academic libraries in higher education. College \& Research Libraries News, Chicago, v. 79, n. 6, p. 286-300, June 2018.

BRAPCI. Disponível em: http://www.brapci.inf.br/index.php/res/. Acesso em: 13 out. 2018.

CARVALHO, Wellington Marçal de; PONTELO, Anália das Graças Gandini; GOMES, Gracielle Mendonça Rodrigues. O Sistema de Bibliotecas da Universidade Federal de Minas Gerais: 90 anos de um organismo em evolução. Ciência da Informação, Brasília, n. 2, v. 46, p. 134-145, maio/ago. 2017.

CUNHA, Murilo Bastos da; CAVALCANTI, Cordelia R. Dicionário de biblioteconomia e arquivologia. Brasília: Briquet de Lemos, 2008.

DIB, Simone Faury; LIMA, Clovis Ricardo Montenegro de. Administração discursiva: uma nova perspectiva para as bibliotecas universitárias brasileiras. Informação@Profissões, Londrina, n. 2, v. 2, p. 92-118, 2013. 
FERNÁNDEZ MARCIAL, Viviana. Inovação em bibliotecas. In: RIBEIRO, Anna Carolina Mendonça Lemos; FERREIRA, Pedro Cavalcanti Gonçalves (Org.). Biblioteca do século XXI: desafios e perspectivas. Brasília: Ipea, 2016.

FOLHA DE SÃO PAULO. Ranking de universidades. São Paulo, 2018.

GOMES FILHO, Antonio Costa; HONESKO, Astrid; SILVA, Vera Lucia Braga da; BEM, Roberta Moraes de. Desafio aos gestores de unidades de informação para implementar o intraempreendedorismo e o empowerment. Informação \& Informação, Londrina, n. 3, v. 16, p. 118-141, 2011.

JULIANI, Jordan Paulesky; VIEIRA, Diego de Castro; MEDEIROS, Déborah; JULIANI, Douglas Paulesky. Design thinking como estratégia de inovação em bibliotecas. Informação \& Informação, Londrina, n. 3, v. 21, p. 101-123, 2016.

JULIANI, Jordan Paulesky; CAVAGLIERI, Marcelo; MACHADO, Raquel Bernadete. Design thinking como ferramenta para geração de inovação: um estudo de caso da Biblioteca Universitária da UDESC. InCID: Revista de Ciência da Informação e Documentação, Ribeirão Preto, n. 2, v. 6 n. 2, p. 6683, 2015.

LION, Samir Elias Kalil; MIRANDA, Zeny Duarte de. Os estilos de funcionamento da liderança nas bibliotecas universitárias do Sistema de Bibliotecas da Universidade Federal da Bahia (SIBI/UFBA): um estudo sobre o Poder organizacional em Unidades de Informação. Pesquisa Brasileira em Ciência da Informação e Biblioteconomia, São Paulo, n. 1, v. 11, p. 135-150, 2016.

MANUAL DE OSLO: diretrizes para coleta e interpretação de dados sobre inovação. 3. ed. [S. I.]: OECD; FINEP, 1997.

MARTINS, Camila Quaresma. Gestão do conhecimento para serviços de informação: análise de produtos e serviços inovadores em Bibliotecas Universitárias. BIBLOS: Revista do Instituto de Ciências Humanas e da Informação, n. 1, v. 26, p. 13-30, 2012.

MARTINS, Robson Dias; CARMO, Annibal José Roris Rodriguez Scavarda do. Criação da cadeia de suprimentos para e-books Supply chain for creation ebooks. Revista ACB: Biblioteconomia em Santa Catarina, Florianópolis, n. 2, v. 20, p. 286-297, 2015.

MODESTO, Fernando. Biblioteca universitária e a inovação: reflexos, definições e descrições. In: SEMINÁRIO NACIONAL DE BIBLIOTECAS UNIVERSITÁRIAS, 20., 2018, Salvador. Anais eletrônicos [...]. Salvador: Repositório Institucional/UFBA, 2018. 
MURIEL-TORRADO, Enrique; GONÇALVES, Marcio. Youtube nas bibliotecas universitárias brasileiras: quem, como e para o que é utilizado. Perspectivas em Ciência da Informação, n. 4, v. 22, p. 98-113, 2017.

OLIVEIRA, Nivaldo; SOUZA, Donizeti Leandro de; CASTRO, Cleber Carvalho de. Análise sociométrica da rede de relacionamento das bibliotecas que constituem o Consórcio das Universidades Federais do Sul-Sudeste de Minas Gerais. Perspectivas em Ciência da Informação, n. 1, v. 19, p. 130-148, 2014.

PASSOS, Ketry Gorete Farias dos; PINTRO, Sirlene; DEVENS FRAGA, Bruna; DANDOLINI, Gertrudes Aparecida; DE SOUZA, João Artur; VARVAKIS, Gregório Jean. Inovação em serviços de informação: uma análise bibliométrica da produção científica. Biblios, Brasília, n. 63, p. 28-43, 2016.

PUC-RIO. Divisão de Bibliotecas e Documentação (DBD). Disponível em: http://www.dbd.puc-rio.br/sitenovo/. Acesso em: 24 nov. 2018.

PUCRS. Biblioteca Central Irmão José Otão. Disponível em: http://biblioteca.pucrs.br/. Acesso em: 24 nov. 2018.

ROSSI, Tatiana. Gestão de competências na prestação de serviços de informação em bibliotecas de universidades da região de Florianópolis. 2012. 198f. Dissertação (Mestrado em Ciência da Informação) - Universidade Federal de Santa Catarina, Florianópolis, 2012.

SAETEREN, Liv. Innovación em los servicios de Biblioteca Pública: el ejemplo de La Deichmanske Bibliotek, la Biblioteca Pública de Oslo. In: JORNADA BIBLIOTECA PÚBLICA I LECTURES, 2005. Anais eletrônicos [...]. Barcelona: Institut del Teatre, 2005.

SALDANHA, Gustavo da Silva. O que é nuvem? Cartas à biblioteca que vem. Revista Brasileira de Educação em Ciência da Informação, São Paulo, n. 1, v. 4 , p. 3-27, 2017.

SCIELO. Coleção da biblioteca. Disponível em: http://www.scielo.br/cgibin/wxis.exe/iah/?lsisScript=iah/iah.xis\&base=article\%5Edlibrary\&fmt=iso.pft\&la ng=p. Acesso em: 13 out. 2018 .

SILVA, Wanessa Caroline da; SILVA, Wanessa Caroline da; ALVES, Maria Bernardete Martins ; DANDOLINI, Gertrudes Aparecida. A biblioteca universitária como um sistema adaptativo complexo (SAC): variação. Revista Brasileira de Biblioteconomia e Documentação, São Paulo, n. 1, v. 13, p. 43-63, 2017. 
TARAPANOFF, Kira. A Biblioteca Universitária vista como uma organização social. Estudos avançados em Biblioteconomia e Ciência da Informação, Brasília, n. 1, v. 1, p. 73-92, 1982.

UCS. Biblioteca. Sistema de bibliotecas. Disponível em: https://www.ucs.br/site/biblioteca/. Acesso em: 24 nov. 2018.

UFMG. Sistema de Bibliotecas da UFMG. Disponível em: https://cerrado.bu.ufmg.br/bu/. Acesso em: 24 out. 2018.

UFPE. Sistema Integrado de Bibliotecas (SIB). Disponível em: https://www.ufpe.br/sib. Acesso em: 24 out. 2018.

UFPR. Sistema de Bibliotecas (SiBi). Disponível em: https://www.portal.ufpr.br/. Acesso em: 24 out. 2018.

UFRGS. Sistema de Bibliotecas da Universidade Federal do Rio Grande do Sul (SBUFRGS). Disponível em: https://www.ufrgs.br/bibliotecas/. Acesso em: 24 out. 2018.

UFRJ. Sistema de Bibliotecas de Informação (SiBi). Disponível em: http://www.sibi.ufrj.br/. Acesso em: 24 out. 2018.

UFSC. Biblioteca Universitária. Disponível em: http://portal.bu.ufsc.br/. Acesso em: 24 out. 2018.

UFV. Florestal. Biblioteca. Disponível em:

http://www.portal.ufv.br/florestal/?page_id=3922. Acesso em: 24 out. 2018a.

UFV. Rio Parnaíba. Biblioteca. Disponível em:

http://www.portal.ufv.br/crp/?page_id=1893. Acesso em: 24 out. 2018b.

UFV. Viçosa. Biblioteca Central Professor Antônio Secundino de São José. Disponível em: http://www.bbt.ufv.br/. Acesso em: 24 out. 2018c.

UNB. Biblioteca Central. Disponível em: https://www.bce.unb.br/. Acesso em: 24 nov. 2018.

UNB. Biblioteca Central. Sobre o Espaço P.O.P. Disponível em: https://www.bce.unb.br/espacopop/sobre-o-espaco-pop/. Acesso em: 23 set. 2019.

UNESP. Coordenadoria Geral de Bibliotecas (CGB). Bibliotecas. Câmpus. Disponível em: https://www2.unesp.br/portal\#!/cgb/bibliotecas-da-rede/campus/. Acesso em: 24 nov. 2018. 
UNICAMP. Sistema de Bibliotecas da Unicamp (SBU). Bibliotecas do

Sistema: [todas]. Disponível em:

https://www.sbu.unicamp.br/portal2/bibliotecas-do-sistema/. Acesso em: 24

nov. 2018.

USP. Sistema Integrado de Bibliotecas (SIBi). Disponível em:

http://www.sibi.usp.br/. Acesso em: 24 nov. 2018.

VALENTIM, Marta Lígia Pomim. O perfil das bibliotecas contemporâneas. In: RIBEIRO, Anna Carolina Mendonça Lemos; FERREIRA, Pedro Cavalcanti Gonçalves. Biblioteca do século XXI: desafios e perspectivas. Brasília: Ipea, 2017.

\title{
INNOVATIVE SERVICES IN UNIVERSITY LIBRARY
}

\begin{abstract}
Introduction: University libraries provide information services that need to be tailored to the needs of faculty, students and administrative staff. For this, purpose, the services are continuously undergoing remodeling. Verifying what is being published about innovative services and trends or what has been offered in other libraries is one aspect to follow. Objective: To identify the innovative services being published and provided in Brazilian university libraries. Methodology: Bibliographic research was used in the BRAPCI and SciELO national databases and documentary research in the library sites of the ten best Brazilian universities and ten most innovative universities. Results: It was observed that most of the retrieved studies area in the Information Science recovered do not address innovation purely and that few services can be identified as innovative in the Brazilian libraries researched. Conclusions: It was verified that university libraries are promoting innovation in their information services, which is possible through partnerships, new ideas, staff training and collaboration, development and / or acquisition of tools and equipment.
\end{abstract}

Descriptors: Information services. Library services. Service innovation. University libraries.

\section{SERVICIOS INNOVADORES EN BIBLIOTECA UNIVERSITARIA}

\section{RESUMEN}

Introducción: Las bibliotecas universitarias brindan servicios de información que deben adaptarse a las necesidades del profesorado, los estudiantes y el personal administrativo. Para esto, los servicios se someten continuamente a remodelación. Un aspecto a seguir es verificar lo que se publica sobre servicios y tendencias innovadores o lo que se ha ofrecido en otras bibliotecas es un aspecto a seguir. Objetivo: Identificar los servicios innovadores que se publican y prestan en las bibliotecas universitarias brasileñas. Metodología: Se utilizó la investigación 
bibliográfica en las bases de datos nacionales BRAPCI y SciELO y la investigación documental en los sitios de la biblioteca de las diez mejores universidades brasileñas y las diez universidades más innovadoras. Resultados: Se observó que la mayoría de los estudios en el área de ciencia de la información recuperados no abordan la innovación exclusivamente y que pocos servicios pueden identificarse como innovadores en las bibliotecas brasileñas investigadas. Conclusiones: Se verificó que las bibliotecas universitarias están promoviendo la innovación en sus servicios de información, lo cual es posible a través de asociaciones, nuevas ideas, capacitación y colaboración del personal, desarrollo y/o adquisición de herramientas y equipos.

Descriptores: Servicios de información. Servicios de biblioteca. Servicio de innovación. Bibliotecas universitarias.

Recebido em: 17.11 .2019

Aceito em: 09.06.2020 